
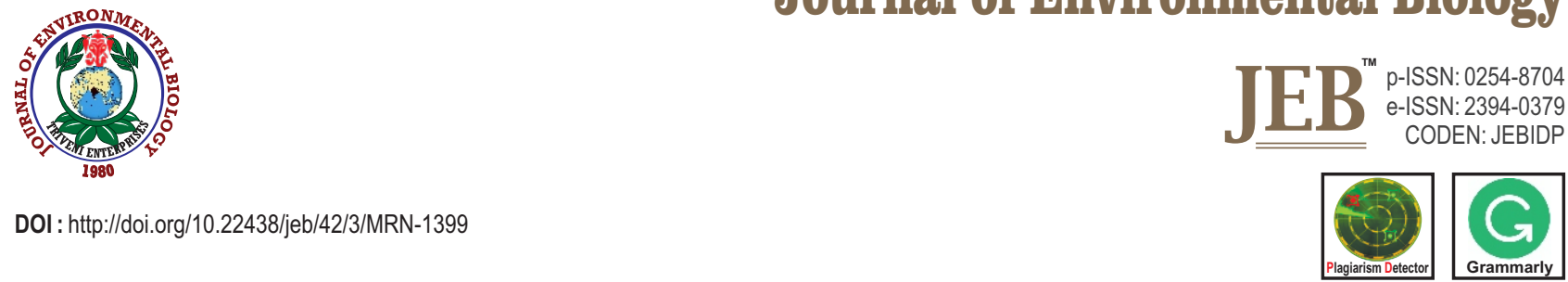

\title{
Exploring genetic variability in ethyl methane sulfonate mediated mutant population of Wagad cultivar of Gossypium herbaceum
}

\author{
U. Kumar ${ }^{1,3}$, S.V. Sawant ${ }^{2,3}$ and H.K.Yadav ${ }^{1,3 *}$ \\ ${ }^{1}$ Plant Genetic Resources and Improvement, CSIR-National Botanical Research Institute, Lucknow-226 001, India \\ ${ }^{2}$ Genetics and Molecular Biology Division, CSIR-National Botanical Research Institute, Lucknow-226 001, India \\ ${ }^{3}$ Academy of Scientific and Innovative Research (AcSIR), Ghaziabad-201 002, India \\ *Corresponding Author Email : h.yadav@nbri.res.in
}

\section{Abstract}

Aim: The aim of the present study was to evaluate the genetic variability in Gossypium herbaceum $(2 n=2 x=26)$ and identification of elite lines for future genetic improvement.

Methodology: The seeds of $G$. herbaceum (cv. Wagad) was treated with 70 mM EMS to develop the mutant population. A set of 235 selected $M_{3}$ mutant families were grown in a random block design (RBD). Genetic (5,500 seeds) variability was evaluated for 14 agromorphological traits.

Results: ANOVA showed significant differences $(P \leq 0.05)$ among the lines for all the traits. The phenotypic (PCV), genotypic coefficient of variability $(\mathrm{GCV})$, heritability in broad sense $\left(h^{2} \mathrm{~B} \%\right)$ and genetic advance (GA\%) were found to be high for most of the

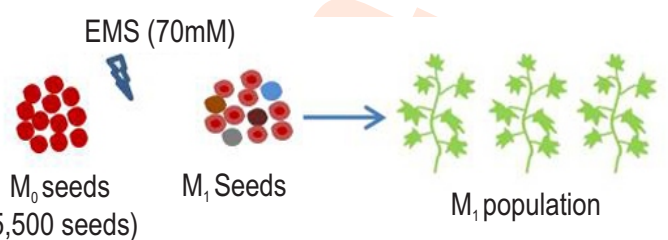
Phenotyping of 235 mutant families for genetic diversity

$\otimes$
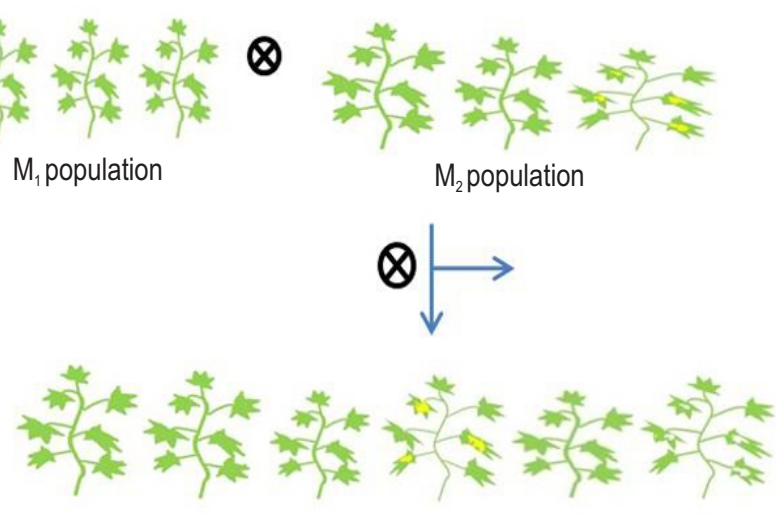

$M_{3}$ population $(235 \times 15=3,525$ plants $)$ traits. The trait association revealed that the biological yield per plant showed a positive and significant correlation with number of bolls/plant, plant height, leaf area, internodal distance, lint weight/plant and seed weight/plant. Path coefficients analysis confirmed that seed weight per plant had a significant role in the yield than other yield components. All the mutant lines were grouped into 16 clusters and exhibited considerable degree of genetic diversity.

Interpretation: The advance mutant lines from distant clusters may be useful for further exploitation for genetic improvement and development of high yielding varieties.

Key words: Gossypium herbaceum, Genetic variability, $\mathrm{M}_{3}$ mutant families

How to cite : Kumar, U., S.V. Sawant and H.K.Yadav: Exploring genetic variability in ethyl methane sulfonate mediated mutant population of Wagad cultivar of Gossypium herbaceum. J. Environ. Biol., 42, 589-596 (2021). 


\section{Introduction}

Cotton (Gossypium spp.) is one of the major source of natural textile fiber, animal feed, and foodstuffs. The genus Gossypium has $\sim 45$ diploids $(2 n=2 x=26)$ and five allotetraploid $(2 n=4 x=56)$ species. Worldwide, $\sim 98 \%$ of lint production comes from two tetraploid viz., G. hirsutum and G. barbadense, and the remaining $2 \%$ is contributed by two diploid species (G. herbaceum and $\mathrm{G}$. arboreum). India stands on top position in cultivation area (10.9 MHa), second in production (33.6 M bales), but has poor yield (522 $\mathrm{kg} \mathrm{ha}^{-1}$ ) than other cotton growing countries. Narayanan et al. (2014) reported tha cotton will share $\sim 25 \%$ of fiber demand for rapidly growing 9.1 billion world population till 2050 with gradual reduction of agricultural land and freshwater supply. Furthermore, due to climate change the ambient temperature will be increased $\sim 5^{\circ} \mathrm{C}$ in the next few decades (Khan et al., 2018). This elevated temperature will enhance evaporation of soil water and limit supply to root system, inviting drought conditions along with various biotic and abiotic stresses.

Since last decade, patchy distribution of rainfal with decreasing water resources is responsible for increased drought conditions and decreased cotton production in India (Ullah et al., 2017). Increasing the lint production will be a big challenge under elevated drought environment. In these circumstances, diploid cotton has more adaptability and innate potential to resist various biotic and abiotic stresses (Kulkarni et al., 2009). Therefore, diploid cotton is preferred more for cultivation in drought-prone regions of Asia. This preferability of diploid cotton has raised the need of creation and exploration of genetic diversity for utilization in crop improvement programme. Genetic diversity helps to develop new varieties with ideal traits such as higher yield, desirable fiber quality, tolerance to pests and diseases. However, the incessant selection for desired traits in elite cultivars forced genetic erosion that narrowed the genetic base and losses rare alleles from improved varieties (Espina et al., 2018). Therefore, mutagenesis is an alternative approach to create genetic variations and broaden the genetic base in a crop.

Spontaneous mutation increases the genetic diversity but at a slow rate $\left(\sim 7 \times 10^{-9}\right.$ nucleotide) (Ossowski et al., 2010). Induced mutagenesis is a powerful tool that can put new alleles in gene pool and broaden the genetic base of concerned crops. Further, this additional genetic diversity can be used for assortment of desirable traits, to break unwanted linkages as well as functional characterization of genes controlling major traits (Patel et al., 2014). Physical (X-ray and gamma-ray) and chemical mutagens (Ethyl methane sulfonate and Sodium azide) are commonly used for inducing mutagenesis in plants. e EMS has been widely used to develop mutant population in various crops (Kurowska et al., 2011). It alkylates guanine (G) residues in DNA which pair with thymine $(T)$ instead of cytosine $(C)$ during DNA replication that promotes GC to AT transition (Kurowska et al., 2011). Various types of genetic materials have been generated in edible/non-edible and model plants by EMS mutagenesis and several targeted traits introduced. Since 1950, joint FAO/IAEA has released 3,283 improved mutant varieties for commercial cultivation. $G$. hirsutum is being used to induce mutagenesis that has resulted in significant traits like good fiber quality (Patel et al., 2014; Herring et al., 2004), disease and drought resistant (Aslam etal., 2016; Witt etal., 2018).

Maharashtra, Gujarat, Madhya Pradesh, Telangana, Andhra Pradesh and Karnataka are major cotton producing states of India that contribute about $60 \%$ of total cultivated area. But, these states comes under-rainfed region having complex climatic deficiencies mainly water scarcity which drastically reduces cotton production. Therefore, there is a need to identify resilient Indian genotypes having tolerance/resistance against biotic and abiotic stresses with higher yield and quality. In previous research conducted at CSIR-National Botanical Research Institute (NBRI), cultivar Wagad of G. herbaceum was found as tolerant to drought in intial growth stages along with difference in physiological response and several new genes were also identified (Ranjan et al., 2012a, b). Thus, the cultivar Wagad has been used for developing EMS derived mutant population. This mutant population can be utilized for functional validation of newly identified drought-related genes and also for varietal development programs. The present study focused to evaluate the performance of selected EMS derived mutant families of $G$. herbaceum, and estimate important genetics parameters as genotypic and phenotypic variability, correlation, path coefficients, and principal component analysis (PCA) for yield and its related traits.

\section{Materials and Methods}

Plant materials and phenotypic evaluation: The plant materials used in the present investigation includes a subset of $235 \mathrm{M}_{3}$ families, selected from $\mathrm{M}_{2}$ generation of $\mathrm{G}$. herbaceum (cv. Wagad) derived from $70 \mathrm{mM}$ EMS treatment. The concentration of lethal dose $\left(\mathrm{LD}_{50}\right)$ of EMS, i.e., $70 \mathrm{mM}$ was determined from $\mathrm{LD}_{50}$ optimization experiment performed at CSIR-NBRI, Lucknow. Based on this experiment, the $70 \mathrm{mM}$ concentration was used in the treatment of large number of seeds (M0 seed) and developed the $M_{1}$ population. The generation advancement of mutant population and other field experiment was conducted at cotton research farm of Mahatma Gandhi Mission (MGM), Aurangabad (MS), India. The experiment with $235 \mathrm{M}_{3}$ families was laid out in random block design (RBD) with 3 replications. Fifteen plants per replications from each selected mutant family (total 10,575 plants) were grown. The plant to plant and row to row space was maintained at $60 \mathrm{~cm}$ and $90 \mathrm{~cm}$, respectively, and followed standard crop management practices. The quantitative data for 14 major agronomical traits (pre and post-harvesting) was recorded from 10 competitive plants per replication. The data were recorded on plant height $(\mathrm{cm})$, mumber of branches per plant, stem circumference $(\mathrm{cm})$, leaf area $\left(\mathrm{cm}^{2}\right)$, number of nodes per plant, internodal distance $(\mathrm{cm})$, number of bolls/plant, seed index (gm), lint weight per plant (gm), seed weight/plant (gm), biological yield/plant (gm), ginning out turn (\%) (lint weight/seed weight $\times 100$ ), lint index (gm) (seed index $\times$ lint $\% / 100$-lint $\%$ ) and harvest index (gm) (economical yield/biological yield×100). 
Statistical Analysis: The pooled phenotypic data was subjected to analysis of various genetics estimates using Windostat software (www.indostat.org). The analysis of variance (ANOVA) and other genetic parameter such as genotypic $\left(\delta^{2} \mathrm{~g}\right)$, phenotypic $\left(\delta^{2} p\right)$, error variance $\left(\delta^{2} e\right)$, genotypic coefficient of variation (GCV), phenotypic coefficient of variation (PCV), broad-sense heritability $\left(h^{2} \mathrm{~B} \%\right)$, and genetic advance as percentage of mean (GA\%) was estimated as per Singh and Chaudhary (1985). The scale for variability was used as high (>20\%), medium (10\%-20\%) and low (<10\%) for PCV, GCV and GA\% (Johnson et al., 1955) while $h^{2} \mathrm{~B} \%$ was categorized as high $(\geq 60 \%)$, moderate $(60-30 \%)$ and low (<30\%) (Robinson et al., 1949). The correlation and path coefficient analysis done as per formula by Johnson et al. (1955). The hierarchical clustering was carried out using Euclidean distance $\left(D^{2}\right)$ statistics based on the pattern of similarity/ dissimilarity using Ward's minimum variance method (Radhakrishna Rao, 1952). To measure the degree of divergence principal component analysis (PCA) was also carried out.

\section{Results and Discussion}

ANOVA revealed considerable degree of differences among the mutant families (Table 1) which ascertains that EMS mutagenesis induces genetic variability in $G$. herbaceum for various traits. Previously, the significant degree of variability has also been reported in the mutant population of Vigna radiata (Wani and Khan, 2006) and Cicer arietinum (Amri-Tiliouine et al., 2018). The estimates of range, mean, phenotypic and genotypic variances $\left(\delta^{2} p\right.$ and $\left.\delta^{2} g\right)$, phenotypic and genotypic coefficient of variation (PCV and GCV), broad-sense heritability (h2B\%), and genetic advance as a percentage of mean (GA\%) are presented in Table 1. The height of plant ranged from 75.0 to $225.0 \mathrm{~cm}$ with an average of $157.54 \pm 7.6 \mathrm{~cm}$. The number of branches per plant varied from 08.0 to $46.0(20.87 \pm 1.10)$ and number of nodes per plant varied from 08.0 to 47.0 with the mean of $25.19 \pm 1.20$. The number of bolls per plant ranged from 11.0 to $62.0(29.98 \pm 1.5)$. The seed and lint yield per plant varied from 22.1 to 111.0 and 11.0 to $55.4 \mathrm{gm}$, respectively. This result indicates that the selected mutant families exhibited intra-population difference as in natural population (Jarwar et al., 2018). The PCV and GCV were observed high for nine agronomical traits viz., number of branches per plant $(34.17 \%$ and $32.93 \%)$, stem circumference ( $28.37 \%$ and $27.11 \%$ ), leaf area (37.13\% and $32.35 \%$ ), number of nodes per plant $(26.23 \%$ and $24.89 \%)$, number of bolls per plant $(30.72 \%$ and $29.49 \%$ ), lint weight/plant (34.19\% and $32.4 \%$ ), seed weight per plant $(33.3 \%$ and $31.66 \%)$, biological yield per plant $(32.94 \%$ and $31.48 \%)$, lint index $(29.66 \%$ and $27.65 \%)$. Similarly, higher PCV and GCV have been reported for various traits in M6 lines of soyabean (Malek et al., 2014). AmriTiliouine et al., (2018) have developed gamma irradiated 135 M2 families of chickpea and reported higher PCV and GCV for yield related traits. In black gram, physical and chemical mutagens have been applied and estimated PCV and GCV different traits (Usharani and Ananda Kumar, 2016). Yusuff et al., (2014) have evaluated 31 mutant lines of rice at different locations and reported high values of PCV and GCV for flag leaf length to width ratio and yield. Laskar and Khan (2017) have estimated high GCV in M3 population of lentil developed by gamma irradiation. In mungbean, high values of PCV and GCV have been reported for major agronomic traits by Roychowdhury et al., (2012), while, Khan and Wani (2006) reported high PCV and GCV for fertile branches/plant. Nurmansyah et al (2020) assessed the genetic diversity in M2 faba bean mutant population for morphological traits. They have identified 36 prominent mutants with altered traits as compare to the control. Among various traits, seed coat colour showed maximum variability in identified mutants. Furthermore, the high PCV and GCV indicates that the induced mutation added genetic diversity as similar to spontaneous mutation.

Table 1: Mean, range and other statistical parameters of genetic variability derived by using 14 agronomic traits in 235 mutant families of Gossypium herbaceum

\begin{tabular}{|c|c|c|c|c|c|c|c|c|c|}
\hline Agronomic trait & Range & Mean \pm SE & F value & $\sigma 2 \mathrm{~g}$ & $\sigma 2 p$ & GCV $\%$ & $\mathrm{PCV} \%$ & $\mathrm{~h} 2 \mathrm{~B} \%$ & GA $\%$ \\
\hline Plant height $(\mathrm{cm})$ & $75-225$ & $157.54 \pm 7.6$ & $15.39^{* *}$ & 851.9 & 1029.43 & 18.51 & 20.36 & 82 & 34.71 \\
\hline Number of branches/plant & $8-46$ & $20.87 \pm 1.10$ & $39.82^{* *}$ & 47.25 & 50.9 & 32.93 & 34.17 & 92 & 65.36 \\
\hline Stem circumference $(\mathrm{cm})$ & $2.8-12.3$ & $5.55 \pm 0.26$ & $32.45^{* *}$ & 2.27 & 2.48 & 27.11 & 28.37 & 91 & 53.36 \\
\hline Leaf area $(\mathrm{cm} 2)$ & $18-154$ & $68.07 \pm 7.14$ & $10.45^{\star *}$ & 484.66 & 638.46 & 32.35 & 37.13 & 75 & 58.06 \\
\hline Number of nodes/plant & $8-47$ & $25.19 \pm 1.20$ & $28.13^{* *}$ & 39.34 & 43.69 & 24.89 & 26.23 & 90 & 48.66 \\
\hline Internodal distance $(\mathrm{cm})$ & $7.5-18.2$ & $12.14 \pm 0.59$ & $13.27^{\star \star}$ & 4.32 & 5.37 & 17.11 & 19.09 & 80 & 31.61 \\
\hline Number of bolls/plant & $11-62$ & $29.98 \pm 1.48$ & $36.09^{* *}$ & 78.2 & 84.88 & 29.49 & 30.72 & 92 & 58.3 \\
\hline Seed index (gm) & $3.8-7.6$ & $6.13 \pm 0.27$ & $4.44^{* *}$ & 0.26 & 0.49 & 8.39 & 11.48 & 53 & 12.64 \\
\hline Lint weight/plant (gm) & $11-55.4$ & $28.78 \pm 1.81$ & $27.39^{\star \star}$ & 86.98 & 96.87 & 32.4 & 34.19 & 89 & 63.25 \\
\hline Seed weight/plant (gm) & $22.1-111$ & $59.29 \pm 3.52$ & $29.23^{\star *}$ & 252.48 & 389.93 & 31.66 & 33.3 & 90 & 62.01 \\
\hline Biological yield/plant (gm) & $35-166$ & $88.01 \pm 4.91$ & $32.67^{\star \star}$ & 767.84 & 840.55 & 31.48 & 32.94 & 91 & 61.98 \\
\hline Ginning out turn (\%) & $26-78$ & $48.89 \pm 2.42$ & $8.61^{* *}$ & 38.36 & 53.47 & 12.66 & 14.95 & 71 & 22.1 \\
\hline Lint index (gm) & 2.3-20.9 & $6.05 \pm 0.40$ & $18.27^{\star *}$ & 2.8 & 3.29 & 27.65 & 29.66 & 85 & 52.59 \\
\hline Harvest index (gm) & $20.8-55.7$ & $32.91 \pm 2.05$ & $2.99^{* *}$ & 8.4 & 21.07 & 8.81 & 13.95 & 39 & 11.46 \\
\hline
\end{tabular}

${ }^{*} \& *$, Significant at 0.05 and 0.01 respectively; $\sigma^{2} g=$ Genotype variance, $\sigma^{2} p=$ Phenotype variance, $G C V=$ Genotypic coefficient of variation, PCV= Phenotypic coefficient of variation, $h^{2} B=$ Broad sense heritability, $G A \%=$ Genetic advance percent of mean 
Table 2: Cluster composition of 16 clusters (Ward's hierarchial clustering) based on multivariate analysis of 235 mutant families of Gossypium herbaceum

\begin{tabular}{lll}
\hline Cluster & $\begin{array}{l}\text { Number } \\
\text { of families }\end{array}$ & \multicolumn{1}{c}{$\mathbf{M}_{3}$ families } \\
\hline I & 32 & $1,30,2,3,6,8,7,18,20,31,13,14,15,21,17,22,16,5,106,137,232,12,155,235,228,11,19,44,45,27,41,25$ \\
II & 25 & $26,33,34,83,79,28,35,84,85,72,74,32,73,81,88,37,38,36,110,116,223,139,192,142,154$ \\
III & 18 & $9,90,10,133,153,157,156,134,89,92,107,91,102,103,108,104,109,101$ \\
IV & 25 & $77,141,93,229,146,96,233,94,78,138,144,140,149,87,148,143,206,230,135,136,145,151,152,150,147$ \\
V & 6 & $4,42,97,95,93,99$ \\
VI & 11 & $29,43,46,132,33,40,80,82,207,231,211$ \\
VII & 8 & $24,182,115,117,203,205,214,126$ \\
VIII & 9 & $179,201,193,200,202,199,204,234,224$ \\
IX & 13 & $105,130,114,184,129,131,119,121,120,188,221,222,225$ \\
$X$ & 2 & 50,51 \\
XI & 3 & $100,125,23$ \\
XII & 25 & $47,49,64,209,75,128,54,189,48,173,174,175,208,194,212,213,62,177,171,160,190,191,172,196,210$ \\
XIII & 19 & $53,57,58,61,67,183,69,197,63,176,178,66,60,65,59,52,70,76$ \\
XIV & 23 & $111,186,118,122,113,183,112,124,181,123,127,187,185,220,56,159,160,162,161,227,163,226,195$ \\
XV & 11 & $71,86,166,170,215,218,158,164,219,165,55$ \\
XVI & 5 & $168,169,217,167,216$ \\
\hline
\end{tabular}

Table 3: The clusters mean values for major morphological traits of 235 mutant families of Gossypium herbaceum

\begin{tabular}{|c|c|c|c|c|c|c|c|c|c|c|c|c|c|c|}
\hline Cluster & $\mathrm{PH}$ & NB & SC & LA & NN & ID & Nbo & SI & LW & SW & BY & GOT & LI & $\mathrm{HI}$ \\
\hline | & 187.85 & 16.43 & 6.06 & 82.21 & 24.38 & 14.94 & 33.59 & 6.24 & 30.90 & 66.44 & 97.60 & 47.04 & 5.52 & 31.57 \\
\hline ॥ & 174.05 & 22.24 & 5.64 & & 24.94 & & & & & 68.60 & 103.80 & 1.35 & 6.48 & 33.71 \\
\hline III & 171.03 & 16.78 & 6.16 & 71.5 & 16.70 & 11.69 & 43.22 & 6.37 & 42.20 & 88.03 & 30.22 & 8.67 & 5.91 & 2.56 \\
\hline IV & 150.52 & 16.98 & 4.34 & 66.95 & 25.29 & 11.44 & 42.98 & 5.99 & 42.69 & 85.92 & 128.21 & 50.34 & 6.27 & 33.45 \\
\hline V & 131.86 & 10.89 & 5.70 & 46.76 & 30.36 & 13.23 & 33.25 & 6.06 & 32.88 & 64.67 & 97.53 & 50.94 & 5.89 & 33.73 \\
\hline VI & 125.02 & 17.42 & 4.21 & 60.41 & 24.93 & 13.18 & 28.83 & 5.90 & 24.85 & 60.20 & 84.73 & 41.27 & 4.45 & 29.32 \\
\hline VII & 122.59 & 15.00 & 4.13 & 39.45 & 23.52 & 11.71 & 21.72 & 5.88 & 22.53 & 36.60 & 58.95 & 61.84 & 7.70 & 38.30 \\
\hline VIII & 175.61 & 17.20 & 4.56 & 68.16 & 24.18 & 11.97 & 17.57 & 6.04 & 18.88 & 34.40 & 51.45 & 49.93 & 6.09 & 37.17 \\
\hline IX & 106.85 & 14.77 & 4.30 & 47.99 & 15.38 & 11.31 & 23. & 6.43 & 21.95 & 47.69 & & 46.45 & 5.85 & 31.82 \\
\hline$x$ & 168.00 & .25 & 7.58 & & & 12.06 & 27.75 & 6. & 27. & 39.48 & & 68.01 & 17.90 & 39.65 \\
\hline XI & 153.00 & 15.67 & 5.16 & 58.01 & 23.16 & 14.44 & 26.94 & 6.03 & 24.80 & 50.61 & 75.41 & 49.14 & 11.42 & 32.94 \\
\hline XII & 152.03 & 34.43 & 5.27 & 75.03 & 36.83 & 10.34 & 23.7 & 6.10 & 21.95 & 45.68 & 67.21 & 48.41 & 5.74 & 33.26 \\
\hline XIII & 163.45 & 26.64 & 5.28 & 56.85 & 29.06 & 10.04 & 27.72 & 6.23 & 24.07 & 53.13 & 77.20 & 45.33 & 5.38 & 31.07 \\
\hline XIV & 151.79 & 25.28 & 5.52 & 56.34 & 24.61 & 12.44 & 20.49 & 6.11 & 19.77 & 39.59 & 59.23 & 49.54 & 5.92 & 33.41 \\
\hline$X V$ & 156.55 & 19.33 & 8.42 & 77.07 & 22.18 & 10.90 & 25.39 & 5.84 & 23.40 & 50.66 & 74.58 & 46.55 & 5.58 & 31.37 \\
\hline $\mathrm{XVI}$ & 157.40 & 20.20 & 11.91 & 67.29 & 20.30 & 11.58 & 24.00 & 5.97 & 23.58 & 47.46 & 73.12 & 50.06 & 5.96 & 32.52 \\
\hline
\end{tabular}

Plant height $=\mathrm{PH}$, Number of branches/plant= NB, Stem circumference $=\mathrm{SC}$, Leaf area $=\mathrm{LA}$, Number of nodes $/$ plant $=$ NN, Internodal distance $=\mathrm{ID}$, Number of bolls/plant $=$ Nbo, Seed index $=$ SI, Lint weight/plant $=$ LW, Seed weight/plant $=$ SW, Biological yield $/$ plant $=$ BY, Ginning out turn $=$ GOT, Lint index $=\mathrm{LI}$ and Harvest index $=\mathrm{HI}$

Heritability is considered to be helpful for predicting the magnitude of phenotypic changes contributed by genetic variability and gives an effective clue for selection of transmitted traits in next generation (Amri-Tiliouine et al., 2018). Here, the broad sense heritability ranged from $39 \%$ (harvest index) to $92 \%$ (number of branches per plant and number of bolls per plant) (Table 1). Agronomically important traits like number of branches per plant, number of bolls per plant, seed weight perplant, lint weight per plant and biological yield exhibited more than $90 \%$ heritability. This explains that these traits are under strict genetic control and least affected by environmental factors (Wondwosen and Abebe, 2017). However, only high heritability does not always mean for high genetic gain because total heritability is defined into additive and non-additive component (Singh and Narayanan, 1993). The expected genetic advance (GA\%) used as a function of selection intensity also play an important role in designing suitable selction strategies (Mishra et al., 2015). Here, the observed GA\% varied from $11.46 \%$ (harvest index) to $65.36 \%$ (number of branches per plant) (Table 1). The number of branches per plant, seed weight per plant, biological yield per 
Table 4: Principal ComponentAnalysis (PCA) for first six principal components (PCs) of 235 mutant families of Gossypium herbaceum

\begin{tabular}{lllllll}
\hline & PC1 & PC2 & PC3 & PC4 & PC5 & Pc6 \\
\hline Eigen value & 19.48 & 13.85 & 10.11 & 7.67 & 6.65 & 4.9 \\
\% of total variance & 26.1 & 18.56 & 13.55 & 10.27 & 8.91 & 6.57 \\
Cumulative variance \% & 26.1 & 44.66 & 58.22 & 68.5 & 77.41 & 83.99 \\
Agronomic trait & & & Eigen Vector & & & \\
PH & 0.37 & 0.15 & 0.78 & 0.78 & 1.15 & 1.3 \\
NB & -3.05 & -0.91 & 1.78 & 0.37 & -0.5 & 0.16 \\
SC & -0.2 & 2.85 & 1.4 & -0.5 & 0.18 & -0.78 \\
LA & 0.4 & 0.56 & 0.63 & 0.52 & 0.56 & 0.45 \\
NN & -0.47 & -1.48 & 0.34 & 0.13 & 1.66 & -1.2 \\
ID & 0.66 & 0.41 & -0.11 & -0.02 & 1.12 & 0.01 \\
Nbo & 2.74 & -1.16 & 1.5 & 0.24 & -0.59 & -0.4 \\
SI & 0.38 & 0.015 & 0.06 & 0.05 & -0.003 & 0.26 \\
LW & 0.81 & -0.37 & 0.9 & -0.31 & -0.234 & 0.17 \\
SW & 0.75 & 0.21 & 0.58 & 0.61 & -0.26 & 0.05 \\
BY & 0.23 & 0.01 & 0.21 & -0.37 & -0.15 & -0.17 \\
GOT & 0.34 & -0.52 & 0.16 & -0.92 & -0.06 & -0.015 \\
LI & -0.6 & -0.5 & 0.53 & -2.19 & 0.45 & 0.69 \\
HI & -0.03 & -0.14 & -0.01 & -0.05 & 0.024 & -0.068 \\
\hline
\end{tabular}

Table 5: Estimation of phenotypic (P) and genotypic (G) correlation coefficients among various quantitative traits of Gossypium herbaceum

\begin{tabular}{|c|c|c|c|c|c|c|c|c|c|c|c|c|c|c|}
\hline Trait & & PH & NB & SC & LA & NN & ID & Nbo & SI & LW & SW & GOT & LI & HI \\
\hline \multirow[t]{2}{*}{ NB } & $P$ & $0.16^{* * *}$ & & & & & & & & & & & & \\
\hline & $G$ & 0.15 & & & & & & & & & & & & \\
\hline \multirow[t]{2}{*}{ SC } & $P$ & $0.31^{* \star *}$ & 0.05 & & & & & & & & & & & \\
\hline & $G$ & 0.3 & 0.04 & & & & & & & & & & & \\
\hline \multirow[t]{2}{*}{ LA } & $P$ & $0.34^{\star * *}$ & 0.07 & $0.17^{\star * *}$ & & & & & & & & & & \\
\hline & $G$ & 0.42 & 0.07 & 0.22 & & & & & & & & & & \\
\hline \multirow[t]{2}{*}{ NN } & $P$ & $0.13^{\star * *}$ & $0.65^{\star * *}$ & -0.04 & $0.08^{*}$ & & & & & & & & & \\
\hline & $G$ & 0.13 & 0.67 & -0.05 & 0.08 & & & & & & & & & \\
\hline \multirow[t]{2}{*}{ ID } & $P$ & $0.22^{\star * *}$ & $-0.25^{\star \star *}$ & $-0.08^{*}$ & $0.15^{\star \star *}$ & $-0.12^{* *}$ & & & & & & & & \\
\hline & $G$ & 0.25 & -0.29 & 0.1 & 0.16 & -0.13 & & & & & & & & \\
\hline \multirow[t]{2}{*}{ Nbo } & $P$ & $0.24^{* * *}$ & $-0.29^{\star \star *}$ & -0.01 & $0.15^{\star \star *}$ & $-0.15^{\star * *}$ & $0.18^{\star *}$ & & & & & & & \\
\hline & G & 0.24 & -0.31 & -0.02 & 0.19 & -0.16 & 0.2 & & & & & & & \\
\hline \multirow[t]{2}{*}{ SI } & $P$ & 0.04 & -0.03 & 0.002 & -0.06 & -0.04 & -0.02 & 0.04 & & & & & & \\
\hline & $G$ & 0.08 & -0.04 & -0.003 & -0.08 & -0.07 & -0.02 & 0.07 & & & & & & \\
\hline \multirow[t]{2}{*}{ LW } & $P$ & $0.20^{\star * *}$ & $-0.28^{* * *}$ & -0.03 & $0.11^{* *}$ & $-0.15^{\star * *}$ & $0.18^{* * *}$ & $0.90^{\star * *}$ & 0.03 & & & & & \\
\hline & G & 0.21 & -0.30 & -0.03 & 0.14 & -0.16 & 0.20 & 0.93 & 0.07 & & & & & \\
\hline \multirow[t]{2}{*}{ SW } & $P$ & $0.22^{\star * *}$ & $-0.28^{* * *}$ & -0.03 & $0.16^{\star * *}$ & $-0.15^{* * *}$ & $0.18^{* * *}$ & $0.92^{* * *}$ & 0.06 & $0.88^{* * *}$ & & & & \\
\hline & $G$ & 0.24 & -0.3 & -0.03 & 0.20 & -0.17 & 0.2 & 0.95 & 0.1 & 0.92 & & & & \\
\hline \multirow[t]{2}{*}{ GOT } & $P$ & -0.03 & -0.04 & -0.02 & -0.06 & 0.02 & 0.03 & 0.03 & $-0.08^{*}$ & $0.26^{\star * *}$ & $-0.15^{\star \star *}$ & & & \\
\hline & $G$ & -0.07 & -0.06 & -0.02 & -0.12 & 0.03 & 0.02 & 0.03 & -0.05 & 0.26 & -0.10 & & & \\
\hline \multirow[t]{2}{*}{ LI } & $P$ & -0.02 & -0.01 & 0.05 & $-0.08^{*}$ & 0.04 & 0.05 & 0.01 & $0.26^{\star * *}$ & $0.14^{* * *}$ & $-0.12^{* *}$ & $0.64^{* * *}$ & & \\
\hline & $G$ & -0.02 & -0.01 & 0.05 & -0.1 & 0.05 & 0.05 & 0.01 & 0.21 & 0.15 & -0.10 & 0.70 & & \\
\hline \multirow[t]{2}{*}{$\mathrm{HI}$} & $P$ & -0.03 & 0.003 & -0.06 & $-0.09^{*}$ & 0.03 & -0.02 & -0.06 & $-0.07^{*}$ & $0.18^{* * *}$ & $-0.19^{\star \star *}$ & $0.68^{\star * \star}$ & $0.41^{* * *}$ & \\
\hline & G & -0.06 & 0.01 & -0.12 & -0.14 & 0.07 & -0.02 & -0.09 & -0.12 & 0.15 & -0.20 & 0.97 & 0.62 & \\
\hline \multirow[t]{2}{*}{ BY } & $P$ & 0.22 & -0.28 & -0.02 & 0.15 & -0.16 & 0.19 & $0.93^{* *}$ & 0.05 & 0.93 & $0.98^{* *}$ & -0.02 & -0.03 & -0.14 \\
\hline & $G$ & 0.23 & -0.31 & -0.02 & 0.18 & -0.18 & 0.21 & 0.96 & 0.1 & 0.96 & 0.99 & 0.02 & -0.01 & -0.09 \\
\hline
\end{tabular}

${ }^{*}$, $*$, Significant at 0.05 and 0.01 respectively; Plant height $=P H$, Number of branches/plant $=$ NB, Stem circumference $=S C$, Leaf area $=L A$, Number of nodes $/$ plant $=$ NN, Internodal distance $=I D$, Number of bolls $/$ plant $=$ Nbo, Seed index $=$ SI, Lint weight $/$ plant $=$ LW, Seed weight $/$ plant $=$ SW, Biological yield $/$ plant $=$ BY, Ginning out turn $=$ GOT, Lint index $=$ Ll and Harvest index $=\mathrm{HI}$ 


\section{D Principal Components Plot}

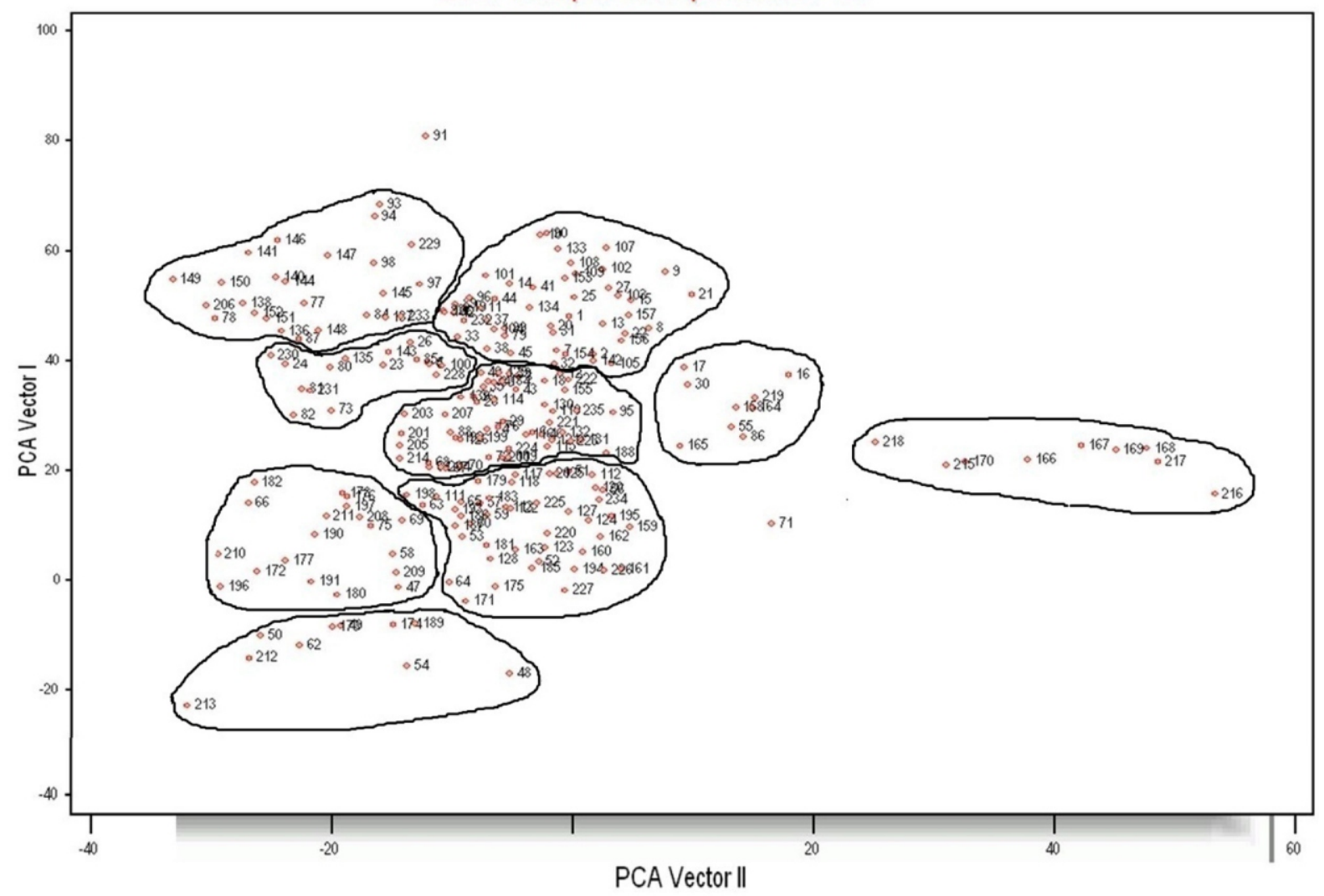

Fig. 1: 2D scatter plot of PC1 and PC2 for 235 mutant families of Gossypium herbaceum.

plant, and lint weight per plant showed both high heritability and high genetic advance. The high GA\% coupled with high heritability is considered to be an important indicator of a greater proportion of additive genetic variance and consequently a high genetic gain expected in coherent (Johnson et al., 1955). The high heritability revealed that most of the traits are primarily controlled by additive gene action, which indicate that selection could be rewading for yield and other yield component traits. Similar findings was also reported in $\mathrm{G}$. arboretum (Wadeyar and Kajjidoni, 2015). Three traits namely seed index, GOT and harvest index showed moderate heritability and GA\% that means these traits might be under the genetic control of various genes and shows non-additive gene action or might be influenced by the environment (Pavan et al., 2018). To determine the potential mutant/groups, phenotypic data was subjected to calculate distance matrix and clustering was done using Wards minimum variance. All the 235 mutant families were distributed in 16 clusters based on the pattern of similarity/dissimilarity among them. The inter-cluster distance varied from 58 (between cluster $\mathrm{XIII}$ and XIV) to 717 (between cluster X and XVI). Whereas, intracluster distance was maximum in cluster $X(234.4)$ followed by cluster XI (85.1) and cluster III (77.8).
The formation of higher number of clusters and large inter-cluster distance showed that the apparent variability have been created in the present materials with EMS mutagenesis. Similarly, significant level of variability also reported by AmriTiliouine et al. (2018), Laskar and Khan (2017), Kumuda and Misra (2008) and Luz et al. (2016). Cluster I comprised largest number of mutant lines (32) followed by cluster II, IV, XII (25), and cluster XIV (23,) while the minimum number of mutant lines was found in cluster $X$ (Table 2). The clusters mean value for different traits showed that the cluster III had the highest mean values for number of bolls per plant (43.22), seed weight per plant $(88.03 \mathrm{~g}$ ), biological yield per plant $(130.22 \mathrm{~g})$ and second highest value for lint weight per plant (42.2g) (Table 3). Likewise, the cluster IV had the highest value for lint weight per plant and second highest value for number of bolls per plant, seed weight per plant and biological yield per plant. Considering the cluster mean value of various traits, the cluster I, II, III, and IV which represents about $42 \%$ of mutant families offers excellent genetic materials.

The lines from these clusters could be utilized as potential genetic material for improvement of levant cotton. It has been advocated thet parental lines selected on the basis of cluster distance might reward more heterosis in their offspring (Malek et 
al., 2014). Previously, diverse lines had been identified from mutant population in different edible and non-edible crops and released for the cultivation purpose. PCA was extracted from all the trait to determine the pattern of variation. The eigen value interconnect to observed variation for principal components (PCs) and eigen vector specify correlation among PCs and original data set. PCA with $>1$ eigen values has been considered and first six PCs accounted $83.96 \%$ of total phenotypic variation (Table 4). The number of branches per plant (-3.05) and number of bolls per plant (2.74) were major contributers for variability in PC1. PC2 was highly associated with stem circumference (2.85), number of nodes per plant (-1.48) and number of bolls per plant (1.16). Third PC was highly related to number of branches per plant (1.78), stem circumference (1.4) and number of bolls per plant (1.5), while PC4 was highly variable for GOT (-0.92) and lint index (-2.19). Fifth and sixth PCs were associated with plant height (1.15 and 1.3) and number of nodes per plant (1.66 and 1.2), respectively (Table 4). The 2D scatter plot of PC1 and PC2, indicated genetic diversity among the mutant families (Fig 1).

The PCA has been widely used for the estimation of genetic diversity using morphological traits in mutant and natural population (Malek et al., 2014; Farooq et al., 2017; Laskar and Khan 2017). The knowledge of trait association and path coefficients helps to devise a suitable breeding strategy for trait improvement (Amri-Tiliouine et al., 2018). The genetic and phenotypic correlation was estimated and presented in Table 5. The magnitude and direction of genotypic and phenotypic correlation coefficients were found to be of similar degree for most of the traits. Similar result has also been reported in $G$. hirsutum by Khalid et al. (2010). The biological yield per plant showed significant and strong positive association with seed weight per plant $(0.98$ and 0.99$)$, number of bolls per plant $(0.93$ and 0.96 ) and lint weight per plant (0.93 and 0.96).

The number of bolls/plant showed significant positive correlation with other yield component traits viz., plant height, leaf area and internodal distance, while negative for number of branches/plant and number of nodes per plant (Table 5). Both the seed weight per plant and lint weight per plant also showed significant positive correlation with plant height, leaf area and internodal distance, in contrast negative association was observed for the number of branches per plant and number of nodes per plant (Table 5). The number of branches per plant, plant height, number of bolls per plant, seed weight per plant and lint weight per plant are efficient contributer to biological yield in desi cotton (Erande et al., 2014) and thus, selection based on above traits may directly or indirectly increase the yield. Further, the path coefficient analysis predicts the influence of casual variables on resultant morphological traits into direct and indirect effects which could enhance the effectiveness of selection (Araújo et al., 2012).

The high direct positive effect noticed for seed weight per plant (1.1648) followed by GOT (0.614) while plant height $(0.0387)$ and number of branches per plant $(0.0118)$ showed direct negligible positive effect. At the same time, plant height showed poor positive indirect effect (0.0736), while number of branches per plant expressed negative effect $(-0.0044)$. The remaining traits showed direct and indirectly negative effect on biological yield per plant. Finally, correlation together with path coefficient analysis revealed that the seed weight per plant has direct relationship with biological yield per plant. The induced mutagenesis is one of the important tools to create new genotypes from elite cultivar without unwanted linkage drag. The phenotypic characterization of selected $M_{3}$ mutant lines revealed considerable level of variability generated through induced mutagenesis and these lines would serve as raw materials for various breeding programs of $G$. herbaceum for further genetic improvement.

\section{Acknowledgment}

Authors thank to director CSIR-NBRI for providing facilities to carry out present work. UK thanks to CSIR for Fellowship (JRF \& SRF).

Funding: Present study was funded by Council of Scientific \& Industrial Research (CSIR) through a project "Genomics of medicinal plants and agronomically important traits (PlaGen)" (BSC 0107).

\section{Add-on Information}

Authors' contribution: U. Kumar: Field layout, maintained all the mutant generations, collected phenotypic data, done all statistical analysis and wrote the manuscript.; S.V. Sawant: designed project and H.K.Yadav: Field layout, revised and edited manuscript.

Research content: The research content of manuscript is original and has not published elsewhere.

\section{Ethical approval: Not applicable}

Conflict of interest: The authors declare that there is no conflict of interest.

\section{Data from other sources: Not applicable}

Consent to publish: All authors agree to publish the paper in Journal of Environmental Biology.

\section{References}

Amri-Tiliouine, W., M. Laouar, A. Abdelguerfi, J. Jankowicz-Cieslak, L. Jankuloski and B.J. Till: Genetic variability induced by gamma rays and preliminary results of low-cost TILLING on $\mathrm{M}_{2}$ generation of chickpea (Cicerarietinum L.). Front Plant Sci., 9, 1568 (2018).

Araújo, L.Fd., W. Almeida, CHCd. M. Bertini, V. das Chagas, F. Neto and E. Bleicher: Correlations and path analysis in components of fiber yield in cultivars of upland cotton. Bragantia, 71, 328-335 (2012).

Aslam, U., H. Cheema, S. Ahmad, I.A. Khan, W. Malik and A.A Khan: COTIP: Cotton Tilling platform, a resource for plant improvement 
and reverse genetic studies. Front Plant Sci., 7, 1863 (2016).

Espina, M.J., C. Ahmed, A. Bernardini, E. Adeleke, Z. Yadegari, P. Arelli, V. Pantalone and A. Taheri: Development and phenotypic screening of an ethyl methane sulfonate mutant population in soybean. Front Plant Sci., 9, 394 (2018).

Erande. C.S., H.V. Kalpande, D.B. Deosarkar, S.K. Chavan, V.S. Patil, J.D. Deshmukh, V.N. Chinchane, A. Kumar, U. Dey and M.R. Puttawar: Genetic variability, correlation and path analysis among different traits in desi cotton (Gossypium arboreum L.). Afr. J. Agric. Res., 9, 2278-2286 (2014).

Farooq, J., M. Rizwan, L. Sharif, S.S.S. Chohan and R. Kainth: Genetic diversity studies in some advanced lines of Gossypium hirsutum L. for yield and quality related attributes using cluster and principle component analysis. Advan. Agricul. Botan., 9,111-118 (2017).

Herring, A.D., D.L. Auld, M.D. Ethridge, E.F. Hequet, E. Bechere, C.J Green and R.G. Cantrell: Inheritance of fiber quality and lint yield in a chemically mutated population of cotton. Euphytica, 136, 333339 (2004).

Jarwar, A.H., X. Wang, L. Wang, Z.H. Jarwar, Q. Ma and S. Fan: Genetic advancement, variability and heritability in upland cotton (Gossypium hirsutum L.). J. Environ. Agricul. Sci., 16, 24-31 (2018).

Johnson, H.W., H. Robinson and R. Comstock: Estimates of genetic and environmental variability in soybeans 1. Agron. J., 47, 314-318 (1955).

Khalid, H., I. A. Khan, H.A. Sadaqat and A. Muhammad: Genotypic and phenotypic correlation analysis of yield and fiber quality determining traits in upland cotton (Gossypim hirsutum). Int. J. Agricul. Biol., 12, 348-352 (2010).

Khan, A., P. Xudong, N. Ullah, K.Y.T. Daniel, F. Shah, Z. Rizwan and L. Honghai: Coping with drought: stress and adaptive mechanisms, and management through cultural and molecular alternatives in cotton as vital constituents for plant stress resilience and fitness. Biol. Res., 51, 47 (2018).

Khan, S. and M.R. Wani: Genetic variability studies for seed yield and its components in mungbean (Vigna radaiata (L.) Wilczek). Thai J. Agric. Sci., 39, 83-88 (2006).

Kumuda, C.M. and R.C. Misra: Genetic divergence analysis among micromutant lines in finger millet (Eleusine coracana G.). J. Crop Sci. Biotech., 11, 63-68 (2008).

Kulkarni, V.N., B.M. Khadi, M.S. Maralappanavar, L.A. Deshapande and S. Narayanan: The worldwide gene pools of Gossypium arboreum $L$. and G. herbaceum L., and their improvement. Genetics and Genomics of Cotton. Springer, pp 69-97 (2009).

Kurowska, M., A. Daszkowska-Golec, D. Gruszka, M. Marzec, M. Szurman, I. Szarejko and M. Maluszynski: TILLING-a shortcut in functional genomics. J. Appl. Genet., 52, 371 (2011).

Laskar, R. A. and S. Khan: Assessment on induced genetic variability and divergence in the mutagenized lentil populations of microsperma and macrosperma cultivars developed using physical and chemical mutagenesis. PLOS ONE, 12, e0184598 (2017).

Luz, V. K., S.F. da Silveira, G. M. da Fonseca, E.L. Groli, R.G. Figueiredo, D. Baretta, M.M. Kopp, A.M. de Magalhães, L.C. da Maia and A.C. de Oliveira: Identification of variability for agronomically important traits in rice mutant families. Bragantia, 75, 41-50 (2016).

Malek, M., M.Y. Rafii, S.S Afroz, U.K Nath and M. Mondal: Morphological characterization and assessment of genetic variability, character association, and divergence in soybean mutants. Sci. World J., 2014, 968796 (2014)

Mishra, R., A.K. Gupta, R.K. Lal, T. Jhang and N, Banerjee: Genetic variability, analysis of genetic parameters, character associations and contribution for agronomical traits in turmeric (Curcuma longa L.). Indus. Crops Produ., 76, 204-208 (2015).

Narayanan, S., P.Vidyasagar and K.S Babu: Cotton germplasm in India- new trends. pp. 87 (2014).

Nurmansyah, S S.Alghamdi and H.M. Migdadi: Morphological diversity of faba bean (Vicia faba L.) M2 mutant populations induced by gamma radiation and diethyl sulfate. J. King Soud. Univ. Sci., 32, 1647-1658 (2020).

Ossowski, S., K. Schneeberger, J.I. Lucas-Lledó, N. Warthman, R.M. Clark, R.G. Shaw, D. Weigel and M. Lynch: The rate and molecular spectrum of spontaneous mutations in Arabidopsis thaliana. Science, 327, 92-94 (2010).

Patel, J.D., R.J. Wright, D. Auld, R. Chandnani, V.H. Goff, J. Ingles, G.J. Pierce, M.J. Torres and A.H. Paterson: Alleles conferring improved fiber quality from EMS mutagenesis of elite cotton genotypes. Theor. Appl. Genet., 127, 821-830 (2014).

Pavan, D., P.K. Moitra, R.S. Shukla, S.S. Shukla, S. Pandey and G. Arya: Analysis of variability, heritability and genetic advance of Yield, its components and quality traits in wheat. Int. J. Agricul. Environ. Biotechnol., 17, 855-859 (2018).

Radhakrishna, R.C.: Advanced Statistical Methods in Biometric Research. John Wiley and Sons, Inc., New York, pp. 390 (1952).

Ranjan, A., D. Nigam, M.H. Asif, R. Sing, S. Ranjan, S. Mantri, N. Pandey, I. Trivedi, K.M. Rai and S.N. Jena: Genome wide expression profiling of two accession of $G$. herbaceum $L$. in response to drought. BMC Genomics, 13, 94 (2012a).

Ranjan, A., N. Pandey, D. Lakhwani, N.K. Dubey, U.V. Pathre and S.V. Sawantx: Comparative transcriptomic analysis of roots of contrasting Gossypium herbaceum genotypes revealing adaptation to drought. BMC Genomics, 13,680 (2012b).

Robinson, H.F., R.E. Comstock and P.H. Harvey: Genotypic and phenotypic correlation in corn and their implications in selection. Agron. J., 43, 282-287 (1949).

Roychowdhury, R., S. Datta, P. Gupta and J. Tah: Analysis of genetic parameters on mutant populations of mungbean (Vigna radiata L.) after ethyl methane sulfonate treatment. Not. Sci. Biol., 4, 137-143 (2012).

Singh, P. and S. Narayanan: Biometrical Techniques in Plant Breeding. Kalyani Publishers, New Delhi (1993).

Singh, R.K. and B.D. Chaundry: Biometrical methods in quantitative genetic analysis. Kalayani Publishers, New Delhi-Ludhiana, 318 pages (1985).

Ullah, A., S. Heng, Y. Xiyan and Z. Xianlong: Drought coping strategies in cotton: increased crop per drop. Plant Biotechnol. J., 15, 271-284 (2017).

Usharani, K.S. and C.R. Ananda Kumar: Estimation of variability, heritability and genetic advance in mutant populations of black gram (Vigna mungo L. Hepper). SABRAO J. Breed. Genet., 48, 258-265(2016).

Wadeyar, B.S. and S. Kajjidoni: Genetic variability estimation and frequency of superior progenies in advance breeding lines in desi cotton at two locations. Curr. World Environ., 10,313 (2015).

Wani, M.R. and S. Khan: Estimates of genetic variability in mutated populations and the scope of selection for yield attributes in Vigna radiata (L.) Wilczek. Egyptian J. Biol., 8, 1-6 (2006)

Wondwosen, W. and B. Abebe: Genetic variability, heritability and genetic advance of some haricot bean (Phaseolus vulgaris L.) varieties at bench-maji zone, Southwest Ethiopia. Asian J. Crop Sci., 9, 133-140 (2017).

Witt, T.W., M. Ulloa, M.G. Pelletier, V. Mendu and G.L. Ritchie: Exploring ethyl methanesulfonate (EMS) treated cotton (Gossypium hirsutum L.) to improve drought tolerance. Euphytica, 214, 123 (2018).

Yusuff, O., M. Y. Rafii, N. Abdullah, M.A. Malek, H. A. Rahim, G. Hussin, M.A. Latif and I. Kareem: Genetic variability and selection criteria in rice mutant lines as revealed by quantitative traits. Sci. World J., 2014, 190531 (2014). 